\title{
Apparatus for the Rapid Determination of the Available Chlorine in Bleach Liquor ${ }^{1}$ \\ By Morris Schrero
}

Research Laboratory, American Writing Paper Co., Holyoke, Massachusetts

The usual paper-mill practice of determining available chlorine in bleach liquor by means of the hydrometer is open to a serious objection, in that there is no definite relation between the specific gravity of the solution and the available chlorine. ${ }^{2}$

Since the customary laboratory methods of titrating bleach liquor are not easily adaptable for use in the mill by men with no chemical training, the apparatus shown in the sketch was designed for the purpose. It has been in use in the mill for over 6 mo. and has given very satisfactory results. It can be used not only for determining the amount of available chlorine in bleach liquor, but for the analysis of permanganate, peroxides, perborates, carbonates, etc.

\section{METHOD}

The method depends upon the measurement of the pressure exerted by the oxygen generated when hydrogen peroxide reacts with hypochlorites in alka. line solution according to the equation:

$$
\mathrm{CaOCl}_{2}+\mathrm{H}_{2} \mathrm{O}_{2}=\mathrm{CaCl}_{2}+\mathrm{H}_{2} \mathrm{O}+\mathrm{O}_{2}
$$

The results obtained by this method do not vary more than $0.02 \mathrm{lb}$. of 35 per cent bleach per gal. from those obtained by titration with sodium thiosulfate. It is probable that if all necessary corrections were made it would be fully as accurate as some of our present laboratory methods.

This method was suggested by an article by $W$. $H$. Chapin, ${ }^{3}$ describing a rapid pressure method for the determination of carbon dioxide in carbonates.

\section{APPARATUS}

The apparatus consists of two bulbs connected by means of a stopcock and a by-pass. The upper bulb has a neck which allows the apparatus to be clamped, and the lower bulb has an opening attached to it at an angle of 5 . 'A manometer

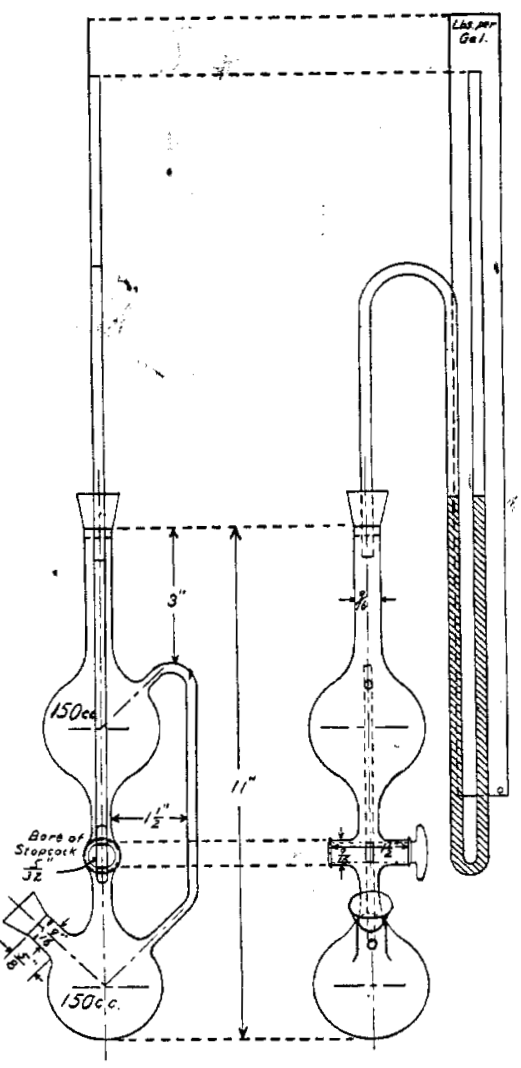
tube is fitted into a rubber stopper, and to this tube is attached a sliding scale, graduated to read in $1 \mathrm{bs}$. of

1 Received February 8, 1921.

2 Ross Campbell, Paper, 20 (1917), No. 14, 11.

3 This Journal, 10 (1918), 527.
35 per cent bleach per gal. of liquor. Readings can be made to hundredths of a pound. It is obvious that the dimensions need not necessarily be those given in the sketch, but they have been found to be the most convenient for a bleach liquor containing about $0.5 \mathrm{lb}$. of 35 per cent bleach per gal. of liquor.

\section{CONSTRUCTION OF SCALE}

The calculations and the calibration of the apparatus are carried out as follows: The volume of the apparatus is determined by filling with water and weighing. The difference between this weight and the weight of the apparatus empty gives, for all practical purposes, its capacity. To determine the volume the evolved gas occupies, the volume of the liquid put into the apparatus must be subtracted from the capacity obtained above. From the equation given above, it can be seen that the amount of oxygen evolved is equivalent to the available chlorine of the bleach liquor. Designating the volume as $V$, the pressure of the oxygen as read on the manometer as $P$, and the temperature as $t$, the following equation corrects the volume $\mathrm{V}$ for temperature and pressure, and gives: Lbs. of 35 per cent bleach per gal. $=$

$$
\frac{\mathrm{V} \times 273 \times \mathrm{P} \times 0.00317 \times 8.33}{(273+t) \times 760 \times 0.35 \times \text { cc.sample }}
$$

where $0.00317=\mathrm{g}$. of chlorine gas per ce. (standard)

$8.33=$ factor to convert $\mathrm{g}$. per cc. to lbs.' per gal.

$0.35=$ wt. of chlorine in one unit of 35 per cent bleach

In plant control work the size of the sample and the volume $\mathrm{V}$ are constant, the temperature $t$ is assumed constant, and hence the bleach strength is directly proportional to $P$. Therefore the equation becomes

Lbs.of 35 per cent bleach per gal. $=\mathrm{KP}$.

The number of $\mathrm{mm}$. of mercury $P$ that would correspond to $0.1 \mathrm{lb}$. of 35 per cent bleach would then be $P=0.1 / \mathrm{K}$.

Having determined the number of $\mathrm{mm}$. that corresponds to $0.1 \mathrm{lb}$. of 35 per cent bleach per gal. of liquor, the scale can be constructed by marking off on any convenient material multiples and submultiples of the number obtained.

\section{PROCEDURE}

In actually using the apparatus, it is first clamped, with the stopcock closed, in a rubber-covered buret clamp. Ten cc. of the bleach liquor are pipetted into the lower bulb, while with another pipet $10 \mathrm{cc}$. of hydrogen peroxide are measured out and put into the upper bulb. The opening in the lower bulb is then tightly stoppered, and the manometer with its attached scale is put into the neck of the upper bulb. The manometer should be tapped gently so that no small particles of mercury adhere to the glass. When the manometer is inserted, there is usually a slight pressure developed, but, for the purposes for which 
this apparatus is intended, this can be disregarded. The stopcock is then opened, allowing the two liquids to come together. In order to make sure of complete reaction, it is usually necessary to shake the apparatus. This is done by placing a finger on the rubber stopper containing the manometer, and the thumb and a finger on the neck of the apparatus, and shaking until the bubbles of gas are set free. The reaction is usually complete in 40 to $50 \mathrm{sec}$. The scale is then adjusted so that the zero point coincides with the top of the lower arm of mercury and the number of $1 \mathrm{bs}$. of 35 per cent bleach per gal. of liquor is read at the mark that coincides with the top of the upper arm of mercury. The whole operation does not take more than 90 to 100 sec.

It is not necessary that the temperature of the apparatus and its conterts be at exactly the temperature for which the scale is graduated. It has been calculated that if the temperature of a bleach liquor that would give a reading of $0.5 \mathrm{lb}$. of 35 per cent bleach per gal. at $22^{\circ}$ C. be $8^{\circ}$ higher or lower than the assumed temperature, the reading would be less than $0.015 \mathrm{lb}$. higher or lower than it should be. In view of the fact that the error in measuring out the liquor in the mills is much greater than this error or those that are introduced by the solution of the oxygen in the liquid, the slight pressure developed on inserting the manometer, etc., corrections need not be made for any of these.

\section{RESUITS}

The results given in the following table were obtained in actual practice by an inexperienced man. The apparatus was kept at the temperature for which the scale was graduated by being placed in a bucket of water. The titrations were made in the laboratory.
By Sodium THiosulfate Titratron Lbs. per Gal.

0.49

0.51

0.42

0.30

0.35

0.28

0.36

0.34

0.28

0.32

0.34

0.30

0.27

0.37

0.38

0.46

ACKNOWLEDGMENT

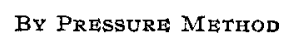

Lbs. per Gal.

0.47

0.51

0.41

0.29

0.36

0.30

0.36

0.33

0.28

0.32

0.34

0.31

0.25

0.39

0.36

0.44
The writer wishes to make acknowledgment to Dr. R. E. Rindfusz, and to Messrs. George G. Taylor and $V$. Voorhees for suggestions and assistance given during the work on this apparatus:

\section{Notes on Laboratory Apparatus ${ }^{1}$}

\section{By A. B. Andrews}

LEWISTON, MaINE

\section{LARGE-CAPACITY AUTOCLAVE}

Some time ago, need arose in this laboratory for a large-capacity autoclave capable of withstanding extreme pressures and heat.

A discarded $150-\mathrm{mm}$. Russian shrapnel case was secured at one of the local munition plants. This case had been rejected on account of warping during the heat treatment and not for any cause of weakness. About 2 in. of the nose were turned off, and the end recessed to retain the packing necessary for tightness. A head, 1.5 in. thick, was turned from a billet of nickel steel, and to this was attached a heavy stuffing box through which passed the shaft of the stirring device. Holes were tapped in the end of the shell, and special nickel-steel cap screws were made to hold on the head. To the head was attached a pressure regulating device from a Stanley steam automobile which was arranged to break an electric contact when a certain predetermined pressure was reached, and which by means of a relay operated a by-pass on the gas main, partly shutting off the gas and allowing the pressure within the autoclave to fall slightly. On making the contact, the gas was again admitted at full volume to the burner, and the pressure slowly rose. This worked perfectly on less than $2 \mathrm{lbs}$. pressure variation, so well, in fact, that often during runs at 600 to 800 lbs. pressure per sq. in., the whole was left unattended and unwatched for days at a time.

1 Received March 10, 1921.
GOLD CATHODES FOR ELECTROLYTIC WORK

Another problem that was successfully solved was the sudden need of several cathodes for electrolytic copper determinations. To avoid the large investment for platinum, if indeed it was available at the time, cathodes of 24-carat gold were tried. They proved to be, to all appearances, the equal of platinum, at one-tenth the price. Since then we have had several open cylinder cathodes, of the same dimensions as the platinum cathodes, in constant use with perfectly satisfactory results. Their weight is very constant, and the deposit is apparently as smooth and desirable as on platinum. Of course, we still have to use platinum as anode. One precaution in using the gold cathode is in igniting to remove any traces of grease; if one is not quite careful, he may slightly fuse the edges or corners. With this exception, these cathodes seem to be the equal of platinum.

\section{Cryogenic Laboratory, Bureau of Mines}

The new low-temperature research laboratory of the Bureau of Mines was dedicated by Mme. Curie on May 21, 1921.

The laboratory is under the direct charge of Dr. R. B. Moore, chief chemist of the Bureau of Mines, and the technical personnel consists of Mr. J. W. Davis, mechanical engineer, of Cornell University and the University of Illinois, Mr. C. W. Seibel, physical chemist, of the University of Kansas, Dr. A. G. Loomis, physical chemist, of the Universities of Missouri and California, and Dr. L. Finkelstein, physical chemist, of the Armour Institute of Technology and the University of Chicago. 